\title{
A Flipped Classroom Approach to Teaching Engineering Mechanics Courses
}

M. Sirigiri,

Teaching Assistant

Arizona State University

Tempe, AZ 85287-5306, USA

\author{
S. D. Rajan \\ Faculty: Civil, Environmental \& Sustainable Engineering Program \\ Faculty: Machanical \& Aero Space Engineering Program \\ School of Sustainable Engineering \& The Built Enviorment \\ Ira A. Falton School of Engineeing Arizon State University \\ Tempe A 285287-5306USA
}

\begin{abstract}
A flipped classroom approach to teaching engineering mechanics courses taught in the 2 nd and 3rd year of a typical undergraduate engineering education, is explained. A combination of few lectures supported by several problem solving recitation classes and continuous assessment, provides both the students and the instructional team an accurate, dynamic picture of the students' understanding and performance. Early use of computer code and openended projects strengthens the understanding of analysis and design techniques in the context of engineering analysis and design. Experience from teaching a 3rd year (junior level) structural analysis and design class for over two decades is shared to draw appropriate conclusions.
\end{abstract}

\section{Sirigiri,}

Teaching Assistant

Arizona State University

Tempe, AZ 85287-5306, USA

\section{Introduction}

Most undergraduate engineering programs that follow $A B E T$ accreditation requirements, are based on 120 to 135 semester hours of coursework that is typically completed in eight semesters. A full-time load is on an average, about 15 semester hours of coursework. Engineering mechanics courses are introduced at the sophomore (2nd year) level and they form the backbone of a number of engineering disciplines - aerospace, biomechanics, civil, materials and mechanical engineering. In an outcomebased educational system, the business of education is more complex than before. As a profession, engineers are expected to deliver goods and services to society, and educating enthusiastic and competent engineers is a challenge.

Fig. 1 shows a typical sequence of courses that civil engineers take. There are five categories of knowledge: mathematics, engineering mechanics, structural bridge, design and advanced analysis courses. A similar diagram can be drawn for other engineering disciplines. The triad of engineering mechanics courses - statics, dynamics and deformable solids, make the foundation on which all advanced mechanics areas are built on. The mathematics courses (differential equations, linear algebra and numerical analysis) provide the problem solving numerical tools that help in finding solutions to routine and more complex problems in a reasonable amount of time and effort. The center piece of the curriculum, structural bridge, connects the knowledge gained in the engineering mechanics courses with the 
more practical side of structural engineering. Towards the end of students' undergraduate career are design and advanced analysis courses that are traditionally associated with the structural engineer moniker.

The flipped classroom instructional mode is a course structure that expects students to learn and explore course content outside of the classroom and complete coursework that may resemble traditional homework assignments during class time. The style enables instructors to spend more time with the students engaged in problem solving over the more traditional approach of lectures, limited recitation, and assessment [1].

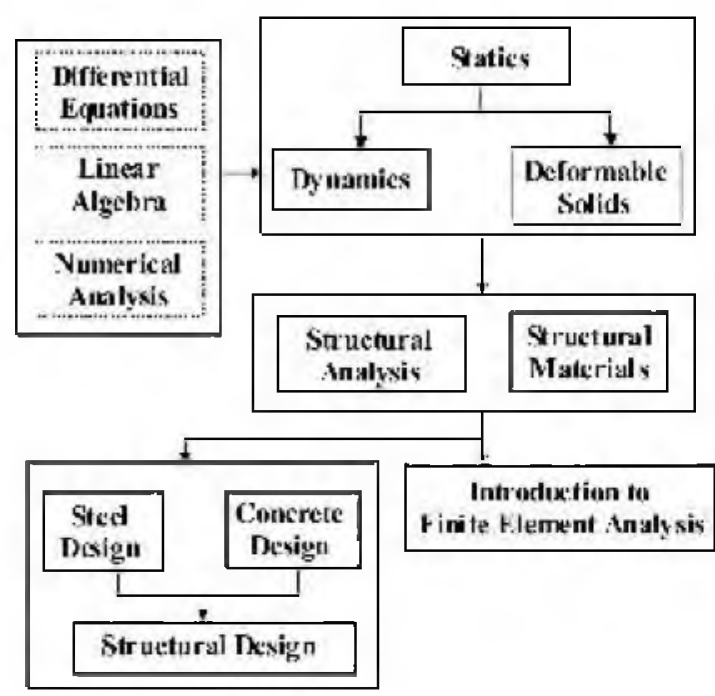

Fig. 1. A typical civil engineering curriculum as related to structural engineering courses

With rapidly evolving technology, the learning habits of students have changed quite dramatically over the last decade. Computers (desktops, laptops, tablets and smartphones) are ubiquitous. Students are more adept at using the internet to search for information that is so much richer than a few textbooks. They are also at home with listening to podcasts or viewing videos. At the same time, the technology to create computer programs, podcasts and videos has evolved so that there are very few constraints placed on the teachers to create a rich learning environment.

We explore the flipped classroom style of education in greater detail in the next section. This is followed by a case study - the teaching of CEE321 Structural Analysis and Design course at Arizona State University. A traditional structural analysis and design course has evolved very slowly where the use of computer programs is only now becoming more prevalent. One of the earliest uses of computer programs for structural analysis education was documented by Brohn [2] who explains that in practice students will be applying computer analysis and should be able to verify the output and correctly interpret results. In a similar effort to encourage students to develop an understanding of structural behavior and response, Allen [3] describes the use of a computer program that allows students to check results with respect to consistency and feasibility rather than modeling and analyzing the system. Both Brohn and Allen's implementation of computer software into the classroom places emphasis on training students to assess computer calculated solutions for reasonableness and feasibility. Clearly, computer software are a small but integral part of the learning process.

We conclude the paper with a few remarks on what can possibly be done to enrich the engineering learning environment in the near term noting that engineers are society's problem solvers.

\section{A Flipped Classroom Style}

A flipped classroom style is one where what is traditionally done in the classroom and what is traditionally done as out-of-class work (e.g. homework) are flipped. For example, if a class typically meets 3 hours per week for lectures after which the students go home and practice and solve problems, they read assigned pages from a text and view lectures videos before coming to class. In the class, they discuss the theory and problem solving details, and then spend the bulk of the time problem solving at their own pace. The expectation is that they would complete and continue the problem solving exercises outside of the classroom. Once an optimal time period has elapsed, the students are assessed their mastery over the subject material. There is increasing evidence that this style leads to increased levels of student achievement, interest, and engagement [4].

\section{A. Use of Various Instructional Resources}

Today a single resource (e.g. textbook) is inadequate. An asynchronous learning mode is essential due to a variety of reasons - students learn in very different ways, some need more time due to inadequate background skills, and all students are not full-time students. Students expect to listen and view 
the lecture material at their own pace. Podcasts and videos certainly assist this learning mode. Furthermore, students expect to see a large number of different solved problems where the nuances of the solution steps are clearly explained. They also expect personalized attention and help 24/7.

\section{B. Optimal Mix of Lectures and Problem Solving}

One cannot do away with lectures completely. However, the amount of time devoted to formal lectures and the instructional style can certainly be changed. A classroom can be made more engaging with active learning. The process starts with student participation in asking and answering questions. The attractiveness of engineering mechanics education is that there are very few identifiable topics that can be clearly structured. The asking and answering questions should be geared towards the theory, assumptions, applications, etc. The bulk of the time must be spent applying the theory to problem solving. This is where the students learn. Innovative teachers use their observations of student learning and problem solving styles to tailor the instructional resources and assessment modes.

\section{The Need for Continuous Assessment}

To assess the effectiveness of both the instructional component and the student's mastery over the subject, there is a need for continuous assessment. There are three major advantages to this: (1) it provides the students a mechanism to demonstrate their knowledge, (2) it provides the teachers immediate feedback on student learning process, and (3) it allows, if necessary, real-time course adjustments to take place.

In the next section, we show how the flipped classroom style is used to teach a junior (3rd year) level structural analysis and design course.

\section{Structural Analysis \& Design}

CEE321 is taught as a required course every fall and spring semester to all civil engineering and construction engineering students at the junior level. It is a structural bridge course (Fig. 1) that relies very heavily on the pre-requisites - statics, dynamics, deformable solids, linear algebra and numerical analysis. The course is a 4 semester hour course that meets three times a week for a total of 4.5 hours. Over the last 4-5 semesters, the class enrollment has steadily increased to between $80-100$ students per semester.

There are three course objectives: (a) to understand and practice structural analysis of determinate and indeterminate structures using classical and matrix methods, (b) to understand and practice simple structural design concepts using structural analysis as a tool, and (c) to learn how to use a general-purpose planar truss and frame analysis computer program for structural analysis and optimal design. These objectives are related to four course outcomes - (a) students will demonstrate mastery of drawing free body diagrams (FBDs) and using FBDs to analyze the structure, (b) students will demonstrate mastery of computing structural response (internal forces, deflections, strains and stresses), (c) students will demonstrate the ability to design truss, beam and frame members and systems, and (d) students will demonstrate the ability to use computer software for structural analysis and optimal design.

The course is taught as a team with the instructor leading the team consisting of a graduate teaching assistant (TA) and 2-3 undergraduate teaching assistants (UGTAs).

\section{A. Instructional Resources}

The class website that is available to the students $24 / 7$, is used to host all instructional resources. These include (a) the course syllabus, (b) all lecture as PowerPoint slides, (c) short ( $<10$ minute) videos on about 40 different topics, (d) recitation problems, (e) supplemental material such as computer programs and sample structural model files, excerpts from structural design codes etc., (f) latest copy of the grade sheet, (g) assignments including design project
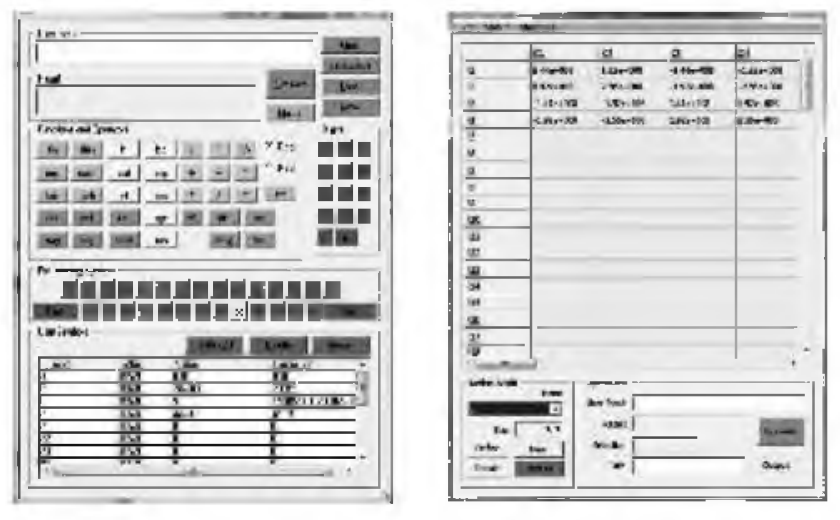

Figure 2. The SlideTray $\overline{\mathbb{C}}$ program showing how the stiffness matrix of a planar truss element is computed. 
statements, (h) an active discussion board where students can post questions and answers, and (i) sample assessment material and solutions from prior semesters. Students are actively encouraged to use the discussion board. They can also meet the TA and instructor one-on-one during office hours (approx. 15 hours/week). Right from the first day, they are strongly encouraged to use numerical tools. An example of a sophisticated GUI-tool is shown in Fig. 2.

\section{B. Lectures and Recitation}

The course is divided into three parts - analysis and optimal design of statically determinate systems, modeling of structural systems using design codes and finite-element based analysis of structural systems, and advanced analysis techniques (analysis of statically and kinematically indeterminate systems using classical and matrix methods). Over the 15week period (or 45 class meetings), there are only about 12 lectures. Before every lecture, students are required to read the textbook, go over the textbook examples, view a short video that introduces the subject matter, and bring the lecture slides to class with their questions. The lecture is used as a questionand-answer session to introduce the theory and solve a few example problems. The bulk of the rest of the time is used in the recitation classes to solve several problems. The instructor, TAs and UGTAs provide assistance including answers to the students.

\section{Continuous Assessment}

A pre-assessment exam is used during the first week of classes to gage the student mastery over the course pre-requisites. The feedback is used by the students to plug any holes in their background. In order to optimally use the instructional team's time, there is no homework in the course. Students are encouraged to complete the recitation problems and solve additional problems from the textbook. Open textbook quizzes (about one per sub-topic) are used to gage the student mastery over the topics. In addition, 1 individual report, 2 team-based design projects (incl. a short technical presentation), 2 mid-terms and a comprehensive final exam, are used as the assessment tools.

\section{Open-ended Team-Based Design Projects}

A significant part of the course is devoted to computation of loads as per design code (ASCE 7-
2010, AAHSTO), using the load combinations on finite element (planar) models of bridges and buildings and designing the structure (sizing, shape, topology and material) for lowest cost. Fig. 3 shows one such student-generated example of a bridge design exercise.

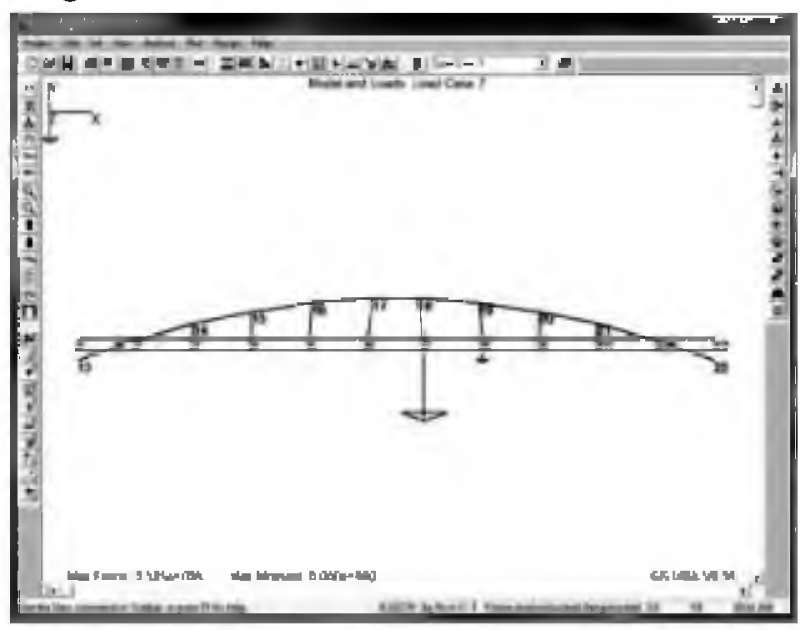

Fig. 3. Computer modeling and optimal design of a bridge subjected to AASHTO code requirements using GS-USA Frame ${ }^{\circ}$ program [5].

The design project has several objectives - (1) understanding why design codes are written and learning how to interpret them, (2) understanding the link between structural analysis and design, (3) learning how to model three-dimensional structural systems, (4) learning how to optimize the design, (5) learning team dynamics and the art of project management, (6) learning how to spot errors and (hand) check results generated by computer programs, and (7) learning how to carefully document the design exercise via technical writing.

\section{Conclusions}

The flipped classroom styled teaching technique adopted in the engineering mechanics courses provides a learning environment that supports student understanding through interactive teaching adjusted to fit the needs of students. There is no substitute for problem solving in engineering especially, engineering mechanics. A talking-head in front of the classroom all the time does not work. Students must be actively engaged and must, on their own, demonstrate that they have a certain level of mastery over the subject material. As we have outlined in this paper, a combination of various instructional resources, and optimal mix of lectures and problem solving, continuous assessment and open-ended, 
team-based design projects provide one encouraging approach to educating the next generation of engineers.

Here is a brief summary of the lessons learnt - (1) students learn in several ways and making an honest effort to cater to the different learning styles pays off in the long run, (2) the primary focus of the learning process should be on the theory not the solution process, (3) the primary focus should be understanding the basics not memorization, (4) to support (3) one must take the focus away from exam scores and focus on assessing the fundamentals, (5) students excel only when challenged (by this we mean that we need to push against the resistance to change, and resistance to self-learning or discovery and resistance to performing as engineering professionals), and (6) for a successful engineering mechanics course, a tightly integrated course is a must where depth of knowledge takes precedence over the width and where exploration of ideas via numerical tools takes precedence over mundane calculations.

\section{Acknowledgment}

The authors would like to thank (a) the rest of the CEE321 instructional team - Krista Mika, Drew
Reasor, Joseph Harrington, Bilal Khalid and Joshua Robbins, who helped teach CEE321 over the last 4 semesters, and (b) colleagues (Amie Stockwell, Keith Hjelmstad and Barzin Mobasher) currently engaged in teaching other mechanics courses using the flipped classroom style.

\section{References}

[1]C.F. Herreid and N.A. Schiller, "Case studies and the flipped classroom", J of College Science Teaching, 42-5, 62-65, 2013.

[2]D.M. Brohn, "The use of the plane frames Program as an Aid to Learning in Structural Analysis", Comput. \& Educ., 5, 37-44, 1981.

[3] H.G. Allen, "Control in the teaching of structural engineering design", Comput. Education, 12:4, 513-520, 1988.

[4] K. Fulton, "Upside down and inside out: Flip your classroom to improve student learning", Learning \& Leading with Technology, 39:8, 12-17, 2012.

[5] S.D.Rajan, “GS-USACFrame Program", [Online]. Available:http://enpub.fulton.asu.edu/structures/r ajansoftware/GS-USA/GS-USAhome.htm, 2013. 